\title{
Terapia Antirretroviral en Adultos Actualización de las Recomendaciones del Panel de la International AIDS Society-USA
}

\author{
Antiretroviral Therapy in Adults. Updated Recommendations of the International AIDS Society-USA Panel.
} Carpenter CC, Cooper DA. JAMA. 2000;283:381-390

El panel para la elaboración de las recomendaciones en el uso de los antirretrovirales en adultos de la International AIDS Society-USA (IASUSA), está constituido por médicos con experiencia en la investigación y desarrollo de drogas antirretrovirales y en el cuidado y atención de pacientes con infección por VIH. Este panel ha ampliado su representación internacional recientemente incluyendo a europeos y australianos. Las presentes recomendaciones representan el consenso de opiniones logrado en diciembre de 1999 que se basó en datos de investigación clínica, básica y en la opinión de expertos.

Fundamentos Científicos para la Actualización de éstas Recomendaciones. Este panel fue constituido en 1995 cuando recién comenzaban los avances alcanzados en el conocimiento del ciclo biológico del VIH, el desarrollo de potentes drogas como los inhibidores de la proteasa (IP) y los inhibidores no nucleósidos de la transcriptasa revesa (INNTR), y el monitoreo de los tratamientos mediante la carga viral. Subsecuentemente se demostró el beneficio del uso de combinaciones de drogas antirretrovirales de alta eficacia, manifestado como una disminución de la morbimortalidad en los pacientes con SIDA. Los estudios seminales de Perelson y Ho en ese mismo año sentaron las bases de la "teoría de la erradicación viral", en la cual una total inhibición de la replicación viral llevaría, luego de un período de aproximadamente dos o tres años, a la total eliminación del VIH del organismo. Todos estos datos fueron la base teórica, para justificar, en ediciones anteriores de éstas recomendaciones, el comienzo del tratamiento antirretroviral precoz y agresivo. Nuevos datos indicaron que aún con una carga viral por debajo de los niveles de detección (< 50 copias/ml) persistía replicación viral de bajo grado. También se descubrió que la vida media de los linfocitos CD4 inactivados, con infección latente en su genoma por ADN proviral de VIH, que inicialmente había sido calculada en 28 días, era en realidad de 6 a 44 meses. De esta manera, la erradicación con terapia antirretroviral únicamente, podría llevar de 10 a 60 años, no constituyendo entonces una meta de tratamiento compatible con la realidad.

La posibilidad de reconstituir el sistema inmune con el control de la replicación viral también se encuentra cuestionada. La destrucción del tejido linfático combinada con la pérdida de los clones celulares de CD4 anti-VIH específicos, sugieren que el tratamiento no restauraría significativamente la función inmunológica, una vez que la inmunocompetencia se ha perdido. Sin embargo, nuevos datos muestran que una reconstitución inmune clínicamente significativa puede ser adquirida en forma lenta y progresiva con una terapia de alta eficacia (HAART en inglés), esto es con la combinación de por lo menos tres drogas, como veremos más adelante.

Por otra parte existe una creciente apreciación de las dificultades generadas con el uso de regímenes antirretrovirales potentes. Aún en ensayos clínicos, las terapias no logran niveles de carga viral $<50 \mathrm{cop} / \mathrm{ml}$ en un número significativo de pacientes. Este dato, sumado a la preocupación por la complejidad de los tratamientos, monitoreo, y adherencia de los mismos, así como las complicaciones por su uso prolongado, sumado al licenciamiento por parte de la FDA (Administración de Drogas y Alimentos de los EE.UU.) de tres nuevos antirretrovirales (efavirenz, abacavir y amprenavir) durante el año pasado, justifican la redefinición de las presentes recomendaciones de tratamiento, destacando que el fundamento del tratamiento de la infección por VIH es el manejo a largo plazo de una infección crónica.

\section{Parámetros clínicos, virológicos e inmunológicos}

El recuento de linfocitos CD4 (Helpers o Ayudantes) y la medición de ARN plasmático del VIH, expresado como carga viral, son elementos, en general, predictores independientes de la evolución clínica. La carga viral es un predictor más poderoso, excepto cuando el recuento de CD4 es muy bajo. Debido a que el proceso de la enfermedad es continuo, el límite utilizado por ambos marcadores para tomar decisiones terapéuticas es, de alguna manera, arbitrario, pero no obstante constituye una guía de utilidad.

Drogas antirretrovirales disponibles

Hay 14 drogas antirretrovirales aprobadas, pertenecientes a tres familias distintas:

- Inhibidores nucleósidos de la transcriptasa reversa (INTR): zidovudina (AZT), didanosina (ddI), zalcitabina (ddC), lamivudina (3TC), stavudina (d4T) y abacavir.

- Inhibidores no nucleósidos de la transcriptasa reversa (INNTR): nevirapina, delavirdina y efavirenz

- Inhibidores de la proteasa (IP): indinavir, saquinavir, nelfinavir, ritonavir y amprenavir.

El VIH, al ser un virus ARN, posee un complejo mecanismo de replicación, requiriendo de varias enzimas para este proceso. Las drogas antes mencionadas actúan inhibiendo dichos pasos metabólicos, impidiendo de esta forma la replicación. La elección de los regímenes no se basa en una simple combinación de las drogas disponibles. Consideraciones prácticas como compatibilidad entre las drogas, efectos adversos y resistencia cruzada, restringen las opciones disponibles, especialmente cuando hay falla en el tratamiento por resistencia. Estrategias a largo plazo son esenciales para maximizar los beneficios terapéuticos: balancear potencia, tolerancia, complejidad del régimen, efectos adversos, riesgo de resistencia y costo. Las presentes recomendaciones están diseñadas para asistir a la toma de decisiones con este objetivo.

Fundamentos para el tratamiento de la Infección por VIH Establecida. A favor:

- La administración de una terapia antirretroviral potente es capaz de restaurar, aunque sea parcialmente, la inmunidad relacionada a los CD4 con memoria antigénica, debido principalmente a la redistribución de los mismos desde el tejido linfático a la circulación.

- En comparación con la infección primaria por VIH (primoinfección), la restauración de la inmunidad específica contra el virus en pacientes con infección crónica por VIH no suele observarse, ni aún con los regímenes más potentes.

- Los linfocitos CD4 "naive" (aquellos que no han estado expuestos a antígenos previamente), fundamentales para la adecuada respuesta antigénica a nuevos antígenos, pueden ser restaurados con una prolongada supresión viral.

- Se ha evidenciado que pacientes que comienzan su tratamiento con cifras de CD4 mayores, alcanzan más rápidamente niveles normales de los mismos.

\section{En contra:}

- Creciente preocupación debido a los efectos adversos a largo plazo de la medicación.

- Problemas en la adherencia de los pacientes a los complejos esquemas de tratamiento.

- Impacto negativo en la calidad de vida.

- Interacciones de las drogas antirretrovirales entre si y con otros fármacos. - Emergencia de resistencia viral.

- Aparición de alteraciones metabólicas, con el riesgo potencial de enfermedad cardiovascular prematura.

Los elementos en contra no deben hacer olvidar el dramático cambio producido por el tratamiento en la morbimortalidad de los pacientes con enfermedad avanzada.

Médicos y pacientes deben balancear riesgos y beneficios de comenzar una terapia antirretroviral, debiéndose individualizar decisiones informadas. Cuándo comenzar tratamiento y que régimen elegir son decisiones cruciales. Elecciones inadecuadas pueden comprometer negativamente futuras opciones.

\section{¿Cuándo se comienza el tratamiento antirretroviral?}

Recomendaciones del inicio del tratamiento antirretroviral

- Pacientes que presentan infección por VIH establecida sintomática. Es decir que presentas síntomas B, muguet, emaciación o "wasting"(caquexia, perdida de peso mayor al $10 \%$ del basal, diarrea crónica, debilidad y fiebre) o alguna enfermedad marcadora de SIDA, independientemente de los niveles de CD4 y carga viral presentes. El tratamiento de infecciones oportunista graves puede anteceder al comienzo de la terapia antirretroviral. 
- Pacientes que presentan infección por VIH establecida asintomática dependiendo de los niveles de CD4 y carga viral. La siguiente tabla resume éstas recomendaciones.

\begin{tabular}{|c|c|c|c|}
\hline \multicolumn{4}{|c|}{ Carga viral en copias/ml } \\
\hline $\mathrm{CD} 4 \mathrm{cel} / \mathrm{mm}$ & $<5000$ & $5000-30.000$ & $>30.000$ \\
\hline$<350$ & Recomendar Terapia & Recomendar terapia & Recomendar terapia \\
\hline $350-500$ & Considerar Terapia & Recomendar terapia & Recomendar terapia \\
\hline$>500$ & Postergar Terapia & Considerar terapia & Recomendar terapia \\
\hline
\end{tabular}

- En pacientes que presentan infección primaria por VIH (primeras semanas o meses de la infección) la indicación del comienzo del tratamiento persiste sin cambios con respecto a la edición anterior, aunque su beneficio clínico no ha sido establecido aún con evidencia suficiente. Debido a éste motivo, se recomienda referir a los pacientes con infección primaria para ser incluidos en ensayos clínicos. En ausencia del acceso a los mismos, una terapia antirretroviral de alta eficacia debe ser ofrecida.

Al igual que en la edición anterior de las presentes recomendaciones, el panel de la IAS-USA hace énfasis en que el tratamiento antirretroviral debe ser discutido con todo los pacientes que tengan infección por VIH establecida. La fuerza de la recomendación de comienzo de tratamiento dependerá del estatus clínico, virológico e inmunológico del paciente, así como también de su deseo de comenzar el tratamiento y su compromiso para adherir a un complejo régimen durante un largo tiempo.

\section{Terapia antirretroviral inicial}

No existen datos definitivos acerca de la superioridad de un régimen aceptablemente potente sobre otro, lo cual dificulta la realización de recomendaciones específicas. La elección de un régimen debe ser individualizada basándose en la fuerza de la evidencia, en la potencia, tolerabilidad, perfil de toxicidad, adherencia, posibilidad de rescate posterior en caso de falla y, cuando están disponibles, resultados de pruebas de resistencia a los antirretrovirales.

En ésta edición, el panel de expertos distingue entre regímenes recomendados (debido a la mayor existencia de estudios prolongados con éstas combinaciones), y regímenes bajo evaluación.

$$
\begin{gathered}
\text { 1. Regímenes Recomendados: } \\
\cdot 1 \text { IP + } 2 \text { INTR } \\
\cdot 1 \text { INNTR + } 2 \text { INTR } \\
\cdot 2 \text { IP + } 2 \text { INTR } \\
\text { 2. Regímenes bajo evaluación } \\
\cdot 3 \text { INTR } \\
\cdot 1 \text { IP + IINTR + INNTR }
\end{gathered}
$$

Los pacientes con un alto riesgo de progresión de la enfermedad (Ej. $\mathrm{CD} 4<50 \mathrm{cel} / \mathrm{mm} 3$ o cargas virales $>100.000$ copias $/ \mathrm{ml}$ ) tienen un bajo índice de respuesta virológica (esto significa que el descenso de la carga viral no alcanza los niveles esperados) con los actuales esquemas de tres drogas. Aunque la efectividad de regímenes más agresivos de inicio ( 4 drogas de las tres clases o regímenes que incluyan 2 IP) es aún incierta, sería adecuado utilizar estas combinaciones más potentes en estos pacientes.

\section{Monitoreo de la Terapia Antirretroviral}

- Adherencia:

La adherencia de los pacientes al tratamiento debe ser evaluada y destacada especialmente. En un estudio se mostró que se requería una adherencia del $95 \%$ para obtener óptimos resultados terapéuticos. Elementos que dificulten la misma, como el número, tamaño y dosis de las píldoras, las restricciones dietéticas, y en particular los efectos adversos deben ser tenidos claramente en cuenta al diseñar un régimen determinado. Antes de comenzar tratamiento debe interrogarse a los pacientes con respecto a sus actividades diarias para identificar eventos cotidianos que puedan utilizarse como recordatorios de los horarios de la medicación. Deben siempre colocarse las instrucciones claramente por escrito. La utilización de pastilleros puede ser de utilidad. Se recomienda evaluar la adherencia en cada visita que realiza el paciente al médico, especialista o de atención primaria. - CD4 y Carga Viral:

Tanto el recuento de CD 4 como los niveles de carga viral son herramientas fundamentales en la decisión de cuándo comenzar tratamiento antirretro- viral y en la evaluación de la respuesta al mismo, especialmente en los pacientes asintomáticos. Se encuentran en la práctica clínica métodos de detección de carga viral con un límite de detección de 40050 copias $/ \mathrm{ml}$.

Se recomienda un mínimo de dos mediciones de CD4 y carga viral, de ser posible en el mismo laboratorio, antes de iniciar o cambiar el tratamiento. Posteriormente se recomienda obtener mediciones al mes de comenzado el tratamiento y a partir de allí, si se tuvo éxito en el descenso de la carga viral, cada dos o tres meses.

La carga viral debe disminuir rápidamente después del inicio del tratamiento. Un descenso mínimo de 1.5 a 2.0 log debe ocurrir alrededor de las cuatro semanas. El nadir de la respuesta se correlaciona con la duración de la misma. Carga virales $>100.000$ copias $/ \mathrm{ml}$ al inicio pueden tomar un tiempo mayor en alcanzar los niveles deseados. La falla en la obtención de niveles < 50 copias/ml para la semana 16 a 24 debe generar preocupación, y considerar las posibles causas de la misma como mala adherencia, inadecuada absorción de las drogas o resistencia viral a las mismas.

El recuento de CD4 irá progresivamente aumentando, dependiendo del grado de deterioro inmunológico inicial.

\section{- Monitoreo del nivel de drogas:}

El rol de dicha medición no ha sido determinado aún en la práctica clínica y se encuentran ensayos clínicos en desarrollo.

Sería de utilidad, entre otros escenarios, en el caso de los IP, en dónde su metabolismo está sujeto a una gran variabilidad personal.

\section{- Prueba de resistencia a las drogas:}

La aparición de resistencia es altamente predictiva de la pérdida de la actividad antirretroviral de un régimen. En la actualidad están disponibles pruebas de resistencia (genotípica y fenotípica), y una adecuada y experta interpretación de las mismas puede mejorar el tratamiento individual de un paciente y reducir el costo y la toxicidad mediante la identificación de cuáles drogas tienen menor probabilidad de ser efectivas. En el presente, el uso de las pruebas de resistencia está limitado por su costo, falta de controles de calidad documentada y de información clínica acerca de su óptimo uso. Una de sus limitaciones principales es que solo expresan los patrones de resistencia de los virus que se encuentran en estado activo de replicación, lo cual no es representativo de las poblaciones virales en estado latente. De ésta forma, las pruebas de resistencia pueden ser útiles en identificàr cuáles drogas no serán activas, pero no podrán garantizar cuáles sí lo serán.

\section{Cambio de Tratamiento}

- Falla de tratamiento:

Ha sido definida ampliamente como una supresión inadecuada de la replicación viral, un insatisfactorio aumento en el recuento de CD4 o la aparición de progresión clínica, excluyendo los signos y síntomas que acompañan a la inmunoreconstitución (fiebre, adenopatías, reacciones inflamatorias en general). Al igual que en la edición anterior de las presentes recomendaciones, no hay aún evidencia de cuál es el nivel de carga viral detectable adecuado para indicar un cambio en el régimen, en términos de la evolución clínica a largo plazo. El mayor riesgo a corto plazo de permitir cualquier nivel de replicación viral, en presencia de tratamiento antirretroviral, es la aparición de resistencia. Niveles de carga viral entre 50 y 500 copias/ml están asociados a mayor riesgo de resistencia que niveles menores de 50 copias $/ \mathrm{ml}$.

La aproximación inicial frente a la aparición de falla virológica, es la evaluación de la adherencia al tratamiento. También debe considerarse la pérdida de potencia del régimen debido a interacciones adversas entre las drogas que lo constituyen.

\section{- Efectos tóxicos e inconveniencias del régimen:}

El aumento de la durabilidad de los regímenes actuales ha hecho advertir de los posibles efectos adversos de aparición tardía en los tratamientos. Si una droga individual en un régimen es cambiada para reducir la toxicidad o para conveniencia del paciente (lo que implica una mejor calidad de vida debido a menor cantidad de píldoras, posología más cómoda, etc), el régimen entero debe ser revisado en referencia a la potencia, la resistencia residual y las interacciones entre las drogas. Si un régimen exitoso es inaceptable debido a inconveniencia, un cambio en la terapia puede ser conside- 
rado si el régimen simplificado aumenta las probabilidades de una mejor adherencia.

\section{Elección de nuevos regímenes:}

- En ausencia de falla virológica:

Por toxicidad, por ejemplo, se cambia, únicamente, la droga responsable de la misma, por otra de igual potencia. Una suspensión temporaria de todo el régimen es aconsejable, antes de realizar un cambio, cuando no se identifica cuál es la droga responsable de la toxicidad. Existen casos especiales, como la hipersensibilidad a abacavir, en las cuales no se debe reintroducir la droga, debido a la posibilidad de toxicidad grave y muerte.

\section{- En presencia de falla virológica:}

La misma debe ser evaluada, como se dijo antes, exhaustivamente en sus causas posibles. Si la adherencia es el problema, limitar el cambio a la droga ofensora puede ser suficiente, conservando siempre el principio de igual potencia.

En pacientes con cargas virales bajas pero aún detectables en los primeros meses del tratamiento, descartada la resistencia, el agregado de una nueva droga puede ser una alternativa (intensificación), teniendo en cuenta que ésta estrategia puede agregarle complejidad al régimen, empeorando la adherencia. En pacientes con cargas virales altas no obstante el tratamiento, la aparición de resistencia es la causa más probable. Una vez que la decisión esta tomada, el cambio por un régimen enteramente nuevo está recomendada, teniendo en cuenta potencia, aceptabilidad, tolerabilidad y resistencia cruzada con los componentes del régimen anterior. Debido a que el virus puede no ser resistente a todas las drogas de un régimen, las pruebas de resistencia pueden ser de utilidad en elegir que droga cambiar y que droga dejar. No obstante, no se sabe si existe algún beneficio en esta estrategia sobre la del cambio completo del régimen. Ante la presencia de fallas virológicas múltiples (más de una) no hay evidencia de que una conducta sea mejor que otra hasta el momento. Cuando el cambio en el régimen no puede ser pospuesto (ej. recuento de CD4 menor a $50 \mathrm{cel} / \mathrm{mm} 3$ o síntomas clínicos) hasta que más drogas estén disponibles, seis o más drogas pueden reciclarse entre las tres familias distintas, obteniéndose así una actividad antirretroviral que suele ser variable al corto plazo. También pueden utilizarse las pruebas de resistencia para diseñar los sucesivos regímenes, aunque ésta conducta no ha sido evaluada suficientemente. Existen datos que sugieren que la suspensión temporaria del tratamiento ( 1 ó 2 meses) previa al comienzo de un nuevo esquema terapéutico podría ser de beneficio. Dos tercios de los pacientes presentan una reversión al virus original ("salvaje"), que presenta un perfil de resistencia mucho más benigno. Ésta conducta se encuentra aún en investigación y no pueden hacerse recomendaciones al respecto.

\section{Suspensión del tratamiento antirretroviral}

Basándose en los datos recientes de la persistencia del beneficio clínico e inmunológico en presencia de falla virológica ( esto es cargas virales detectables o en ascenso) es razonable continuar con el tratamiento antirretroviral tanto como sea posible. No obstante, puede requerirse reducción de dosis, sustitución de una o más drogas en el esquema, debido a la toxicidad frecuente en pacientes con enfermedad avanzada.

\section{Comentario}

La modalidad de presentar recomendaciones de tratamiento antirretroviral confeccionadas por un panel de expertos fue iniciada por la IAS-USA en simultáneo con el desarrollo de la XII Conferencia Internacional sobre SIDA en Vancouver, Canadá en 1996, piedra angular de los actuales conocimientos sobre el tema. Posteriormente, y también con actualizaciones anuales, el Departamento de Salud y Recursos Humanos de los EE.UU, con el apoyo de la Fundación Káiser elaboró sus recomendaciones, así como también las Sociedades Británicas y Francesas de SIDA.

Diferencias en la interpretación de los datos por parte de los miembros de los distintos paneles Llevaron a las grandes diferencias existentes en las versiones anteriores de las distintas recomendaciones. En la actualidad la expansión del conocimiento basado en la evidencia, ha disminuido el área de desacuerdo. El disenso continúa en aquellas áreas que persisten relacionadas a la "opinión de expertos" que interpretan en forma diferente los aún escasos datos sobre:

A) El momento óptimo para comenzar tratamiento en los pacientes asintomáticos.

B)Cual es la mejor combinación para iniciar el tratamiento

C) Cual es el mejor momento para cambiar un tratamiento que se encuentra en falla.

Los consensos de tratamiento producidos en los EE.UU, como el que hoy comentamos, propugnan aún un comienzo precoz del tratamiento (cargas virales $>5000$ copias $/ \mathrm{ml}$ en pacientes con $\mathrm{CD} 4<500 \mathrm{cel} / \mathrm{mm} 3$ ). Este criterio no es compartido por sus contrapartes europeas, firmemente embarcadas en un criterio más conservador (cargas virales $>30.000$ copias $/ \mathrm{ml} 0$ $\mathrm{CD} 4<350 \mathrm{cel} / \mathrm{mm} 3$ ). La falta de una clara evidencia al respecto genera estas notables diferencias. La postura europea, más conservadora y pragmática frente a la escasez de datos definitivos es la que, a mi parecer, más se adecua a la realidad de la práctica médica diaria, fuera de los "microclimas" de los ensayos clínicos. Esta idea se sostiene debido a:

1. La imposibilidad de erradicar completamente el VIH con los esquemas actuales de tratamiento

2. La prevalencia alarmante de efectos adversos de las drogas a largo plazo (lipodistrofia, osteoporosis, diabetes, etc.)

3. La dificultad en lograr una adecuada adherencia en un plazo prolongado 4. La falta de evidencia de la superioridad de una conducta más agresiva, sobre otra más conservadora

Corrientes de cambio se perciben también desde Los EE.UU. En un artículo de perspectiva publicado recientemente en el Annals of Internal Medicine, el Dr. Keith Henry de St. Paul, Minesota hace una profunda reflexión (considerada herética por la "nomenklatura" de expertos en VIH americanos) haciendo un llamado por una terapia antirretroviral más cauta y "centrada en el paciente". El sentido común y el buen sentido médico, es decir el de la evidencia, nos orientan en ésta dirección.

\section{¿Cuál es la realidad de la terapia antirretroviral en la Argentina?}

En nuestro país existen recomendaciones del Ministerio de Salud Pública, que están inspiradas en las de la IAS-USA que acabamos de comentar. La medicación antirretroviral está asegurada en forma gratuita por la ley de Plan Médico Obligatorio, que involucra a las empresas de medicina prepaga, a las obras sociales y a los hospitales nacionales, municipales y provinciales. Las 14 drogas antirretrovirales autorizadas por la FDA se encuentran en el mercado argentino, aunque la provisión de alguna de ellas en el Plan Nacional de SIDA, esto es en el ámbito público, dependerá de las licitaciones de turno, que muchas veces utiliza genéricos de bioequivalencia desconocida.

\section{Dr. Ricardo A. Mackintosh}

Departamento de Medicina Interna, CEMIC.

\section{Bibliografía}

1. Department of Health and Human Services and Henry J. Kaiser Family Foundation. Guidelines for the use of antiretroviral agents in VIH infected adults and adolescents. Published online at http:/NIHatis.org. May 1999.

2. BVIHA Guidelines Co-ordinating committee. British VIH Association guidelines for antiretroviral treatment of VIH seropositive individuals. Lancet 1997;349:1086-1092.

3. Gazzard B, Moyle M, on behalf of the BVIHA Guidelines Writing Committee. 1998 revision to the British VIH Association guidelines for antiretroviral treatment of VIH seropositive individuals. Lancet 1998;352:314-316 BVIHA. Lancet 1997;349:1086-1092.

4. VIH-1 RNA response to antiretroviral treatment in 1280 participants in the Delta Trial: an extended virology study. Delta Coordinating Committee and Delta Virology Committee. AIDS 1999:13(1):57-65.

5. The Case for more Cautious, Patient-Focused Antirretroviral Therapy. Annals of Internal Medicine, 1999 132: 306-311.

6. Carr A, Samaras K, Burton S, et al. A syndrome of peripheral lipodystrophy, hyperlipidaemia and insulin resistance in patients receiving VIH protease inhibitors. AIDS. 1998;12:F51-F58 